\title{
Dynamic transcriptional changes in response to rehydration in Anabaena sp. PCC 7120
}

\author{
Correspondence \\ Masayuki Ohmori \\ ohmori@molbiol.saitama-u.ac.jp
}

Received 23 April 2007

Revised 12 June 2007

Accepted 30 July 2007
Akiyoshi Higo, ${ }^{1,2}$ Takayuki Suzuki, ${ }^{1,2}$ Masahiko Ikeuchi ${ }^{2}$ and Masayuki Ohmori ${ }^{1}$

\author{
${ }^{1}$ Department of Molecular Biology, Faculty of Science, Saitama University, 255 Shimo-Ohkubo, \\ Sakura-ku, Saitama City, Saitama 338-8570, Japan \\ ${ }^{2}$ Department of Life Sciences (Biology), University of Tokyo, Komaba 3-8-1, Meguro, \\ Tokyo 153-8902, Japan
}

\begin{abstract}
Global transcriptional responses to dehydration and rehydration were determined in Anabaena sp. PCC 7120. Nearly 300 genes were up- or downregulated during both dehydration and rehydration. While as many as 133 genes showed dehydration-specific downregulation, only 29 genes showed dehydration-specific upregulation. In contrast, while only 13 genes showed rehydration-specific downregulation, as many as 259 genes showed rehydration-specific upregulation. The genes upregulated during rehydration responded rapidly and transiently, whereas those upregulated during dehydration did so gradually and persistently. The expression of various genes involved in DNA repair, protein folding and NAD synthesis, as well as genes responding to nitrogen depletion and $\mathrm{CO}_{2}$ limitation, was upregulated during rehydration.

Although no genes for transcriptional regulators showed dehydration-specific upregulation, eight showed rehydration-specific upregulation. Among them, two genes, ancrpB and alr0618, encode putative transcriptional activators of the cAMP receptor protein (CRP) family. DNA microarray analysis using gene disruptants revealed that $\mathrm{AnCrpB}$ and $\mathrm{Alr0618}$ regulate the genes induced by nitrogen depletion and by $\mathrm{CO}_{2}$ limitation, respectively. We conclude that rehydration is a complex process in which the expression of certain genes, particularly those for metabolism, is dramatically induced.
\end{abstract}

\section{INTRODUCTION}

Desiccation-tolerant organisms are able to retain their cellular components during desiccation and rapidly resume metabolism when they are rewetted after prolonged desiccation (Potts, 1994, 2001). It is widely believed that the accumulation of disaccharides, such as trehalose and sucrose, during the dehydration process confers desiccation tolerance. However, it has become increasingly clear that true desiccation tolerance is likely to involve several mechanisms working in concert. These include the scavenging of reactive oxygen species, the downregulation of metabolism, and the accumulation of certain amphiphilic solutes, proteins and polysaccharides (Oliver et al., 2001). The cellular responses to desiccation and rehydration are distinct from one another and are equally complex (Shaw et al., 2003; Singh et al., 2005). The strictly regulated

Abbreviations: CRP, CAMP receptor protein; ROS, reactive oxygen species; RuBisCO, ribulose bisphosphate carboxylase.

The microarray data for this paper have been deposited in the KEGG expression database; accession numbers are given in the text.

Seven supplementary tables with details of the up- and downregulated genes are available with the online version of this paper. resumption of cellular metabolic processes is required on rehydration (Potts, 1994; Scherer et al., 1984). Furthermore, some damage to DNA and membranes becomes manifest upon rehydration (Potts, 1994).

The $\mathrm{N}_{2}$-fixing filamentous cyanobacteria Nostoc commune can survive repeated cycles of desiccation and rehydration (Potts, 1994, 1999; Shaw et al., 2003). Desiccated N. commune rapidly recovers its photosynthetic activity after being soaked (Satoh et al., 2002; Scherer et al., 1984; Tamaru et al., 2005). An extracellular substance, such as exopolysaccharide (EPS), seems to function in desiccation tolerance (Helm et al., 2000; Hill et al., 1994a, b, 1997; Scherer \& Potts, 1989; Shaw et al., 2003; Shirkey et al., 2000; Tamaru et al., 2005; Wright et al., 2005). Only a few studies of the intracellular mechanism of desiccation tolerance have been reported (Shirkey et al., 2000; Xie et al., 1995).

Anabaena sp. PCC 7120 (hereafter Anabaena PCC 7120), which is a close relative of the desiccation-tolerant Nostoc sp. HK-01 (Katoh et al., 2003), is also tolerant to desiccation, although only weakly (Higo et al., 2006; Katoh et al., 2004). The genome sequence of Anabaena PCC 7120 has been completely determined (Kaneko et al., 
2001) and a genetic transformation system has been developed (Elhai et al., 1997). We have shown that Anabaena PCC 7120 accumulates large amounts of sucrose but only small amounts of trehalose $(0.05-0.1 \%$ of dry weight), although trehalose is important for desiccation tolerance (Higo et al., 2006). We have also previously reported microarray analysis of the genome-wide gene expression changes during dehydration (Higo et al., 2006; Katoh et al., 2004).

In this study, we performed DNA microarray analysis during rehydration following dehydration. We discuss the similarities and differences in transcriptional profiles during dehydration and rehydration. Whereas no genes encoding transcriptional regulators were specifically upregulated during dehydration, eight were specifically upregulated during rehydration. Of these, we focused on ancrpB and alr0618, encoding putative transcriptional regulators of the cAMP receptor protein (CRP) family.

\section{METHODS}

Strains, growth conditions, and dehydration and rehydration treatments. Anabaena PCC 7120 (wild-type strain) and gene disruptants were grown at $30{ }^{\circ} \mathrm{C}$ at $40 \mu \mathrm{mol}$ photons $\mathrm{m}^{-2} \mathrm{~s}^{-1}$ in nitrogen-free modified Detmer's medium $\left(\mathrm{MDM}_{0}\right)$ (Watanabe, 1960) until late-exponential phase. $\mathrm{MDM}_{0}$ medium contains, per litre: $13 \mathrm{mg} \mathrm{CaCl}_{2} \cdot 2 \mathrm{H}_{2} \mathrm{O}, 0.25 \mathrm{~g} \quad \mathrm{MgSO}_{4} \cdot 7 \mathrm{H}_{2} \mathrm{O}, 0.1 \mathrm{~g} \mathrm{NaCl}, 0.25 \mathrm{~g}$ $\mathrm{K}_{2} \mathrm{HPO}_{4}, 20 \mathrm{mg} \mathrm{FeSO}{ }_{4} \cdot 7 \mathrm{H}_{2} \mathrm{O}$ and $1 \mathrm{ml}$ trace elements $\mathrm{A}_{6}$ (Kratz \& Myers, 1955). Liquid cultures were bubbled with air containing $1.0 \%$ $(\mathrm{v} / \mathrm{v}) \mathrm{CO}_{2}$.

Dehydration stress was imposed on cells as described previously (Higo et al., 2006). A $30 \mathrm{ml}$ portion of cell culture was filtered onto cellulose acetate filter paper $(0.45 \mu \mathrm{m}$ pore size, $47 \mathrm{~mm}$ diameter; Advantec) and dried for $24 \mathrm{~h}$ at $30{ }^{\circ} \mathrm{C}$ at $30-40 \mu \mathrm{mol}$ photons $\mathrm{m}^{-2}$ $\mathrm{s}^{-1}$ in a Petri dish. After dehydration for $24 \mathrm{~h}$, cells on the filter paper were rehydrated in $30 \mathrm{ml} \mathrm{MDM}$ and incubated as described above for the indicated times.

DNA microarray analysis. RNA was extracted from cells as described previously (Katoh et al., 2004). DNA microarray analysis with an Anabaena oligonucleotide microarray (Ehira \& Ohmori, 2006; Higo et al., 2006) (Sigma-Aldrich) was performed according to the method described previously (Higo et al., 2006) with some modifications.

A mixture of RNA and Anabaena primer mix (Ehira \& Ohmori, 2006; Higo et al., 2006) (Sigma-Aldrich) in an $11 \mu$ volume was heated to $90{ }^{\circ} \mathrm{C}$ for $5 \mathrm{~min}$, and then gradually cooled to $42{ }^{\circ} \mathrm{C}$ for $20 \mathrm{~min}$. Reverse transcription was performed at $42{ }^{\circ} \mathrm{C}$ for $90 \mathrm{~min}$ in a $20 \mu \mathrm{l}$ volume containing $5 \mu \mathrm{g}$ RNA, Anabaena primer mix (3.44 nM each ORF), $1 \times$ first-strand buffer $(50 \mathrm{mM}$ Tris/ $\mathrm{HCl}, 75 \mathrm{mM} \mathrm{KCl,} 3 \mathrm{mM}$ $\left.\mathrm{MgCl}_{2}, \mathrm{pH} 8.3\right), 10 \mathrm{mM}$ DTT, $250 \mu \mathrm{M}$ each dATP, dGTP and dCTP, $200 \mu \mathrm{M}$ dTTP, $50 \mu \mathrm{M}$ Cy3-dUTP or Cy5-dUTP, 200 U SuperScript II Reverse Transcriptase (Invitrogen) and $20 \mathrm{U}$ RNase inhibitor (Takara). The RNA in the reaction mixtures was hydrolysed by incubation at $70{ }^{\circ} \mathrm{C}$ after the addition of $10 \mu \mathrm{l} 0.1 \mathrm{M} \mathrm{NaOH}$, after which the mixtures were neutralized by the addition of $15 \mu \mathrm{l} 1 \mathrm{M}$ Tris/ $\mathrm{HCl}(\mathrm{pH}$ 7.5). Two reaction mixtures (one labelled with $\mathrm{Cy} 3$ and the other labelled with Cy5) were combined and purified with a QIAquick PCR Purification kit (Qiagen) to remove unincorporated fluorescent nucleotides. The purified cDNA solution was vacuumconcentrated to about $10 \mu \mathrm{l}$. The cDNA solution $(9.4 \mu \mathrm{l})$ and $3.3 \mu \mathrm{l}$
$20 \times$ saline sodium citrate (SSC) were combined and denatured at $95{ }^{\circ} \mathrm{C}$ for $5 \mathrm{~min}$. The mixture was cooled at room temperature, then $0.65 \mu \mathrm{l} 10 \%(\mathrm{w} / \mathrm{v})$ SDS was added.

The microarrays were hybridized, washed and scanned as described previously (Ehira et al., 2003). The relative expression ratio for each oligoDNA spot was defined as the normalized fluorescence intensity for each DNA spot at each time point relative to that at time zero (before dehydration). The experiments were performed twice independently, with different combinations of $\mathrm{Cy}$ dyes. Thus, the relative ratio for each DNA spot is represented by four measurements.

The means and standard deviations of the ratios of the transcript levels at each time point relative to those of the control were calculated as base-2 logarithms. A gene was judged to be upregulated when its mean relative ratio was greater than 1.6 (equivalent to threefold induction) with $P$ value (Student's one-sample $t$ test against 0 ) of less than 0.01. A gene was judged to be downregulated when its mean relative ratio was less than -1.6 (equivalent to threefold repression) with $P$ value (Student's one-sample $t$ test against 0 ) less than 0.01 .

The microarray data have been deposited in the KEGG expression database (http://www.genome.jp/kegg/expression/), with the following accession numbers. Anabaena PCC 7120 (wild type strain): dehydration for $3 \mathrm{~h}$, ex0001765-0001768; dehydration for $9 \mathrm{~h}$, ex0001769-0001772; dehydration for $24 \mathrm{~h}$, ex0001773-0001776; rehydration for $20 \mathrm{~min}$, ex0001777-0001780; rehydration for $1 \mathrm{~h}$, ex0001781-0001784; rehydration for $3 \mathrm{~h}$, ex0001785-0001788. Anabaena ancrpB disruption mutant: dehydration for $24 \mathrm{~h}$, ex0001789-0001792; rehydration for $20 \mathrm{~min}$, ex0001793-0001796; rehydration for $1 \mathrm{~h}$, ex0001797-0001800; rehydration for $3 \mathrm{~h}$, ex0001801-0001804. Anabaena alr0618 disruption mutant: dehydration for $24 \mathrm{~h}$, ex0001805-0001808; rehydration for $20 \mathrm{~min}$, ex0001809-0001812; rehydration for $1 \mathrm{~h}$, ex0001813-0001816; rehydration for $3 \mathrm{~h}$, ex0001817-0001820.

Inactivation of ancrpB and alr0618. To inactivate the gene ancrp $B$ (alr2325) (Suzuki et al., 2004), a DNA fragment from the ancrpB region of Anabaena PCC 7120 was amplified by PCR using primers $5^{\prime}$-ACTACTCAATTTACCCTC- ${ }^{\prime}$ and $5^{\prime}$-CCCGGGCGTTCTCTAGAAATACTG- $3^{\prime}$ or $5^{\prime}$-CCCGGGGCATCATAGAATGCTGCA-3' and 5'-GTCAAGAATTGGTGATGA-3'. Their respective PCR products were cloned into the pGEM-T Easy vector (Promega). Both plasmids were digested with ScaI and SmaI, and were ligated together, generating a plasmid with a new SmaI restriction site at the centre of ancrpB. The $\Omega S \mathrm{p}^{\mathrm{r}}-\mathrm{Sm}^{\mathrm{r}}$ cassette excised with $S m a \mathrm{I}$ was inserted into the SmaI site present in the inserted DNA fragment of ancrpB. The EcoRI fragment from this plasmid was blunted with Klenow fragment and then ligated into vector pRL271 (Cai \& Wolk, 1990) digested with NaeI.

To inactivate the gene alr0618, a DNA fragment from the alr0618 region of Anabaena PCC 7120 was amplified by PCR using primers 5'-AAGCTGCGAGGATTGGTCTA-3' and 5'-GGATCCCGTGAAATTTGTTCCAGGG-3' or 5'-GGATCCGCCGAGAAATTGAATGCGAT- $3^{\prime}$ and $5^{\prime}$-TCTGAGCATACTTCCACTCG- ${ }^{\prime}$. Their respective PCR products were cloned into the pGEM-T Easy vector. Both plasmids were digested with PstI and $B a m H I$, and were ligated together, generating a plasmid with a new BamHI restriction site at the centre of alr0618. The $\Omega S \mathrm{p}^{\mathrm{r}}-\mathrm{Sm}^{\mathrm{r}}$ cassette excised with BamHI was inserted into the BamHI site present in the inserted DNA fragment of alr0618. The fragment digested from this plasmid with PstI and NsiI was ligated into vector pRL271 (Cai \& Wolk, 1990) digested with PstI.

ancrpB and alr0618 were inactivated with sacB-mediated positive selection for double recombination (Cai \& Wolk, 1990). Transformation of Anabaena PCC 7120 was performed by a conjugation method (Elhai \& Wolk, 1988), and both single and 
double recombinations were confirmed by PCR. Completely segregated clones of the mutants were used for the study.

Northern blotting analysis. This was carried out as described previously (Higo et al., 2006). The cmpA probe was synthesized with a DIG PCR synthesis kit (Roche Molecular Biochemicals) using primers 5'-CCCTTCACAGCTGCTCAAAC- ${ }^{\prime}$ ' and 5' -GCCATGAAACCGACTTTGTC-3'.

Measurement of oxygen-evolving activity. Oxygen-evolving activity was measured in intact cells with or without $5 \mathrm{mM}$ $\mathrm{NaHCO}_{3}, 10 \mathrm{mM}$ HEPES (pH 7.5), using a Clark-type oxygen electrode (Rank Brothers) at a light intensity of $1000 \mu \mathrm{mol}$ photons $\mathrm{m}^{-2} \mathrm{~s}^{-1}$ at $30{ }^{\circ} \mathrm{C}$. Light was provided by a halogen lamp. The absorbance of chlorophyll extracted by methanol was measured at $665 \mathrm{~nm}$ and the chlorophyll concentration was calculated from the equation $1 A_{665}$ unit=13.42 $\mu \mathrm{g}$ chlorophyll ml ${ }^{-1}$ (Mackinney, 1941).

\section{RESULTS}

\section{Genes up- or downregulated during both dehydration and rehydration}

RNA was extracted after $24 \mathrm{~h}$ of dehydration and after $20 \mathrm{~min}, 1 \mathrm{~h}$ and $3 \mathrm{~h}$ of rehydration. The expression profiles at each time point were compared with that before dehydration with the Anabaena oligonucleotide microarray. The DNA microarray data were analysed in reference to the data for dehydration for $3 \mathrm{~h}$ and $9 \mathrm{~h}$ (Higo et al., 2006).

We found that the expression of 399 genes was upregulated during dehydration and the expression of 769 genes was upregulated during rehydration when compared with their expression levels before dehydration. Among those upregulated genes, 292 genes overlapped (Fig. 1a and Supplementary Table S1, available with the online version of this paper). The genes induced under both conditions were classified into two patterns in terms of the time of maximum gene expression. (1) More than half of them showed maximum gene expression not only in $3 \mathrm{~h}$ or $3-$ $24 \mathrm{~h}$ of dehydration but also in 1-3 h of rehydration. Many of these genes encode hypothetical and unknown proteins, while genes for trehalose metabolism were also included in this category (Higo et al., 2006). (2) The rest of the genes showed maximum expression between late dehydration and early rehydration. Among these genes, those for chaperones and proteases were markedly upregulated upon rehydration, suggesting that the control of protein quality is important after rehydration.

The expression of 583 genes was downregulated during dehydration and 492 genes were downregulated during rehydration. Among these, 289 genes overlapped (Fig. 1b and Supplementary Table S2). Most of these genes are involved in various cellular processes, such as photosynthesis, ATP synthesis, nitrogen fixation, cell wall synthesis and translation, which are essential for growth. The transcription levels of the downregulated genes were restored gradually during the rehydration period (1-3 h). Genes for ATP synthesis, photosystem II and ribosomal proteins recovered early, whereas genes for photosystem I and nitrogen fixation recovered later.

\section{Dehydration-specific gene expression change}

To exclude the genes with obscure peaks of up- or downregulation, the mean ratios at dehydration were compared with those at rehydration. We assessed whether they differed significantly using Student's two-sample $t$ test. Of the 107 genes that were judged to be upregulated during dehydration (Fig. 1a), only 29 clearly showed maximum transcriptional level during dehydration (Supplementary Table S3). Many of these showed maximum transcriptional level during later dehydration (9-24 h). Of these, 26 genes encode hypothetical or unknown proteins. The rest encode thioredoxin, alcohol dehydrogenase and transglycosylase. In contrast, of the 299 genes downregulated during (a) Up-regulated

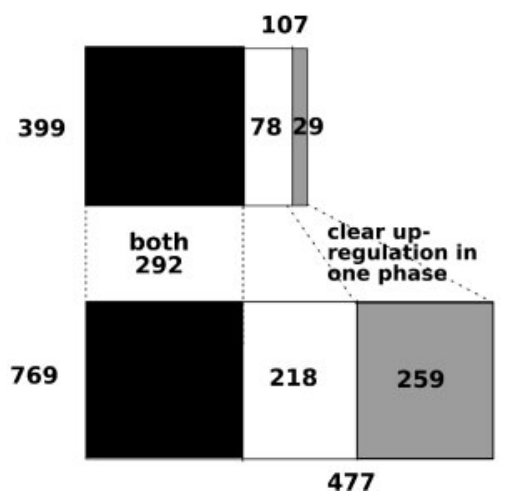

(b) Down-regulated

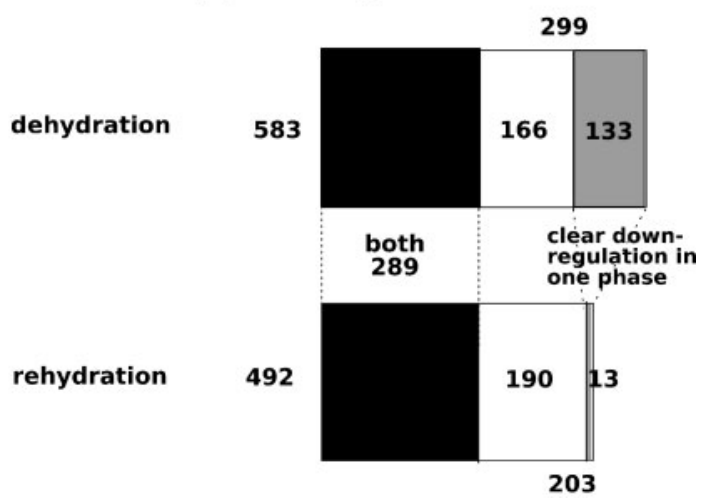

Fig. 1. Number of genes upregulated (a) or downregulated (b) during dehydration (top) and rehydration (bottom). Black bars, number of genes up- or downregulated in both phases; grey bars, number of genes showing a clear maximum (a) or minimum (b) transcriptional level in only one phase; white bars, number of genes which did not show a clear peak in one phase. 
dehydration (Fig. 1b), 133 clearly showed minimum transcriptional levels during dehydration (Supplementary Table S4). Gene expression of many of those that had been downregulated after $3 \mathrm{~h}$ of dehydration were restored immediately after rehydration. Representatives of these include genes encoding ribulose bisphosphate carboxylase (RuBisCO), FtsZ and some ribosomal proteins. Expression of genes involved in central cellular energy metabolism was restored in a stepwise manner.

\section{Dynamic transcriptional response to rehydration}

Of the 477 genes that were upregulated during rehydration (Fig. 1a), 259 clearly showed maximum transcriptional level in the rehydration phase (Supplementary Table S5). Many of these genes showed rapid and transient upregulation with a maximum transcriptional level within $1 \mathrm{~h}$ of rehydration. These 259 genes were classified into the following functional groups: (a) protein folding and degradation; (b) DNA repair; (c) metabolism; (d) signal transduction; and (e) other, hypothetical and unknown function. It was noted that expression of a gene orthologue to Synechocystis sp. PCC 6803 hik34, the product of which regulates genes for chaperones and proteases (Paithoonrangsarid et al., 2004; Suzuki et al., 2005), was upregulated upon rehydration.

Forty genes upregulated on rehydration were also upregulated by nitrogen depletion (Ehira \& Ohmori, 2006). Nitrogen metabolism in cyanobacteria is generally regulated by NtcA, a global nitrogen-responsive transcriptional regulator protein (Herrero et al., 2001), and ntcA was downregulated during dehydration and was also slightly downregulated during rehydration (data not shown). The gene expression patterns of many NtcA regulons and the genes involved in heterocyst formation were similar to that of $n t c A$. This suggests that genes upregulated during both rehydration and nitrogen depletion are independent of NtcA regulation.

As many as 57 genes related to various cellular metabolic reactions were sequentially upregulated during rehydration (Fig. 2). Quinolinate synthase (NadA) encoded by all4673, PncB encoded by alr2482, and NadD encoded by alr 2483 are required for NAD biosynthesis (Gerdes et al., 2006), suggesting the depletion of the NAD pool during rehydration. Other genes markedly upregulated during rehydration were the suf operon (alr2492-alr2495), which has been shown to function in the assembly of iron-sulfur clusters under conditions of oxidative stress (Nachin et al., 2001). Rewetting the cells would cause oxidative stress (Potts, 1994). The remaining genes are involved in respiration (cytochrome $c$ oxidase), the pentose phosphate pathway (ribulose-phosphate 3-epimerase), lipid synthesis (diacylglycerol kinase), and nitrogen and amino acid metabolism. Of the 203 genes that were downregulated during rehydration (Fig. 1b), only 13 showed minimum transcriptional level in the rehydration phase (Supplementary Table S6).

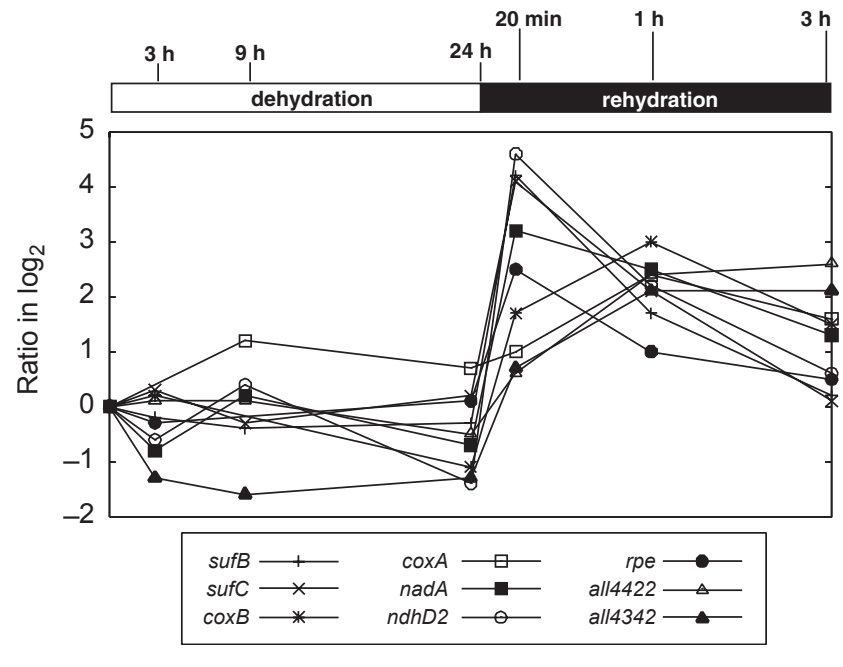

Fig. 2. Changes in the transcript levels of representative metabolic genes upregulated during rehydration. sufB and sufC, iron-sulfur cluster assembly protein; $\operatorname{cox} A$, cytochrome $c$ oxidase subunit I; $\operatorname{cox} B$, cytochrome $c$ oxidase subunit II; nad $A$, quinolinate synthase; $n d h D 2, \mathrm{NADH}$ dehydrogenase subunit 4 ; rpe, pentose5-phosphate 3-epimerase; all4422, UDP-N-acetyl-D-mannosamine transferase; all4342, mannose-6-phosphate isomerase.

\section{Transcriptional regulator genes upregulated during rehydration}

No genes involved in signal transduction displayed dehydration-specific upregulation (Supplementary Table S3). Among genes showing rehydration-specific upregulation (Supplementary Table S5), eight encode transcriptional regulators (Table 1) and six belong to a transcriptional repressor family. The remaining two genes, ancrpB and alr0618, encode CRP family transcriptional activators, and the former gene product binds to cAMP (Suzuki et al., 2004).

Table 1. Transcription factor genes upregulated during rehydration

\begin{tabular}{|cccccc|}
\hline Gene & Family & Dehydration & \multicolumn{4}{c|}{ Rehydration $^{*}$} \\
\cline { 3 - 6 } & & $\mathbf{2 4} \mathbf{~ h}$ & $\mathbf{2 0} \mathbf{~ m i n}$ & $\mathbf{1 ~ h}$ & $\mathbf{3 ~ h}$ \\
\hline $\begin{array}{c}\text { alr2325 } \\
(\text { ancrpB })\end{array}$ & $\mathrm{CRP}$ & $1.0 \pm 0.5$ & $2.2 \pm 0.7$ & $2.9 \pm 0.4$ & $0.6 \pm 1.5$ \\
alr0618 & $\mathrm{CRP}$ & $-1.3 \pm 0.5$ & $3.1 \pm 0.5$ & $1.6 \pm 0.3$ & $-1.2 \pm 0.6$ \\
alr0810 & TetR & $0.0 \pm 0.9$ & $3.4 \pm 1.1$ & $2.9 \pm 0.4$ & $-0.2 \pm 0.4$ \\
alr1721 & TetR & $0.7 \pm 0.4$ & $3.3 \pm 0.9$ & $1.6 \pm 0.4$ & $1.1 \pm 0.3$ \\
alr4279 & TetR & $0.2 \pm 0.5$ & $2.9 \pm 0.9$ & $2.5 \pm 0.4$ & $0.7 \pm 0.8$ \\
alr0957 & FUR & $0.6 \pm 0.3$ & $2.5 \pm 0.4$ & $0.8 \pm 0.3$ & $0.4 \pm 0.4$ \\
$(\mathrm{f} u r C)$ & & & & & \\
all2491 & DeoR & $1.0 \pm 0.4$ & $2.9 \pm 0.4$ & $0.6 \pm 0.3$ & $0.4 \pm 0.2$ \\
$($ sufR $)$ & & & & & \\
alr4908 & LexA & $-1.4 \pm 0.6$ & $-0.7 \pm 0.7$ & $0.8 \pm 0.2$ & $2.6 \pm 0.2$ \\
$($ lexA $)$ & & & & & \\
\hline
\end{tabular}

${ }^{\star}$ Means $\pm \mathrm{SD}$ of ratio in $\log _{2}$. 
Anabaena AnCrpB binds to the consensus DNA sequences of Escherichia coli CRP. However, AnCrpB seems to lack the ordinary DNA-binding domain (Suzuki et al., 2004). An HMMSEARCH with the HMMER2.2 software package (Eddy, 1998) against the C-terminal sequence of AnCrpB using the CRP Pfam profile (PF00325) resulted in a negative bit score, but in an $E$-value of $10^{-3}$. This means that the C-terminal sequence of AnCrpB is a distant homologue of the DNA-binding CRP family.

As regards the $\mathrm{N}$-terminal sequence of both $\mathrm{AnCrpB}$ and Alr0618, they both possess a cNMP-binding domain. AnCrpB has a cAMP-binding motif and it binds cAMP (Suzuki et al., 2004). In contrast, Alr0618 does not have the motif, suggesting that this protein does not bind cAMP.

\section{Effect of ancrpB and alr0618 disruption on gene expression during rehydration}

To identify the genes regulated by AnCrpB and Alr0618, DNA microarray analysis was performed using disruptants of the corresponding genes. The genes that were upregulated by rehydration in the wild-type strain, but not in the ancrpB disruptant, are shown in Table 2. Twenty-two of 33 genes were upregulated after $20 \mathrm{~min}$ of rehydration only in the wild-type strain (Table 2), suggesting that ancrpB is involved in gene expression at early rehydration. The expression of five genes was upregulated by nitrogen deprivation (Table 2) and that of another five genes was also slightly upregulated by nitrogen deprivation (Ehira \& Ohmori, 2006). This suggests that AnCrpB regulates the expression of genes related to nitrogen depletion.

Table 3 shows that the expression of 20 genes was upregulated by rehydration in the wild-type strain, but not in the alr0618 disruptant. The expression patterns of alr4157 (ndhD3)-alr4158 (cupA), and alr2877 (cmpA)alr2878 (cmpB), encoding components of the NdhD3/ $\mathrm{NdhF}$ /CupA NAD(P)H dehydrogenase complex essential for growth under low- $\mathrm{CO}_{2}$ conditions and components of the high-affinity bicarbonate transporter, respectively, were similar to that of alr4156 (ndhF3), although the standard deviations were rather high (Supplementary Table S7). Northern blotting analysis using a that the entire cmp operon (alr28-77-alr2880) is upregulated by rehydration in the wild-type strain, but not in the alr0618 disruptant (Fig. 3). These genes in two gene clusters are orthlogues of genes induced under inorganic carbon limitation in Synechocystis sp. PCC 6803 (Wang et al., 2004). It is suggested that Alr0618 regulates the expression of genes related to inorganic carbon uptake.

\section{Contribution of ancrpB and alr0618 to the recovery of photosynthesis during rehydration}

Oxygen-evolving activities were measured during rehydration as an indicator of the recovery of the cells (Fig. 4). In the wild-type strain, approximately $30 \%$ of the oxygen-evolving activity was restored within $30 \mathrm{~min}$ of rehydration. This activity gradually returned to the level before rehydration within $24 \mathrm{~h}$ (data not shown).

To determine the physiological function of ancrpB and alr0618 during rehydration, oxygen-evolving activities were measured in the wild-type strain and the $\operatorname{ancrpB}$ and alr0618 disruptants (Fig. 4). Before dehydration, this activity was the same amongst all these strains. In the absence of bicarbonate, during the first $2 \mathrm{~h}$, oxygenevolving activity of the ancrpB disruptant was only slightly lower than the wild-type strain, whilst that of the alr0618 disruptant was similar to the wild-type (Fig. 4a). However, the oxygen-evolving activities in the ancrpB and the alr0618 disruptants were $60-75 \%$ of that in the wild-type strain after $2 \mathrm{~h}$ of rehydration. In the presence of bicarbonate, there was no difference in oxygen-evolving activity between the wild-type and the alr0618 disruptant, while the activity of the ancrpB disruptant was lower than in the wild-type strain (Fig. 4b). These results suggest that these CRP family transcription factors are required for the recovery of photosynthetic activity during late rehydration. alr0618 is related to inorganic carbon uptake in particular.

\section{DISCUSSION}

\section{Similarities and differences in transcriptional responses to dehydration and rehydration}

We performed a comprehensive analysis of transcriptional profiles during dehydration and rehydration in Anabaena PCC 7120 and found that the expression of as many as 292 genes was upregulated during both dehydration and rehydration (Fig. 1a). These genes are thought to be general stress-responsive genes, involved in switching from a metabolism directed toward maximal growth to a maintenance metabolism (Hengge-Aronis, 2002). In dry yeast, 'stationary-phase-essential genes' and those induced during both desiccation and rehydration are similar (Singh et al., 2005). These genes might not be stimulated by a specific environmental stress, but rather by reduced metabolic states (Singh et al., 2005).

The results of the present work show that the downregulation of genes is marked during dehydration, whereas the upregulation of genes is marked during rehydration. This suggests that endurance of a stress is important during dehydration, whereas the rapid repair of damage and the resumption of metabolism are important during rehydration. A striking feature of the upregulation of gene expression during rehydration is the dynamic changes, a response that is markedly different from the upregulation of genes during dehydration. A feature of the latter was a gradual change and persistence (Katoh et al., 2004). These results reflect a difference in the dehydration and rehydration processes, the former being gradual, and the latter rapid.

In this study, the Anabaena cells were dehydrated for $24 \mathrm{~h}$ and then rehydrated. Previous data showed that the wet 
Table 2. Effects of the disruption of $\operatorname{ancrpB}$ on the upregulation of gene expression during rehydration

Results in bold represent significant upregulation of genes at the time points compared to dehydration phase in the wild-type strain, but not in the gene disruptant strains.

\begin{tabular}{|c|c|c|c|c|c|c|c|c|c|}
\hline \multirow[t]{3}{*}{ Gene } & \multirow[t]{3}{*}{ Description } & \multicolumn{4}{|c|}{ Wild-type strain ${ }^{\star}$} & \multicolumn{4}{|c|}{ ancrpB disruptant* } \\
\hline & & \multirow{2}{*}{$\begin{array}{c}\text { Dehydration } \\
24 \mathrm{~h}\end{array}$} & \multicolumn{3}{|c|}{ Rehydration } & \multirow{2}{*}{$\begin{array}{c}\text { Dehydration } \\
24 \mathrm{~h}\end{array}$} & \multicolumn{3}{|c|}{ Rehydration } \\
\hline & & & $20 \mathrm{~min}$ & $1 \mathrm{~h}$ & $3 \mathrm{~h}$ & & $20 \mathrm{~min}$ & $1 \mathrm{~h}$ & $3 \mathrm{~h}$ \\
\hline asl0171 & Hypothetical protein & $0.3 \pm 0.3$ & $2.0 \pm 0.3$ & $1.4 \pm 0.1$ & $0.8 \pm 0.2$ & $1.6 \pm 0.9$ & $0.9 \pm 0.6$ & $-0.1 \pm 0.7$ & $0.0 \pm 0.5$ \\
\hline allo334 & Hypothetical protein & $-0.2 \pm 0.4$ & $1.8 \pm 0.3$ & $1.1 \pm 0.4$ & $0.4 \pm 0.5$ & $0.5 \pm 0.6$ & $1.2 \pm 0.6$ & $0.8 \pm 0.3$ & $0.4 \pm 0.3$ \\
\hline alr0774 & Two-component response regulator & $-1.0 \pm 0.3$ & $2.0 \pm 0.7$ & $0.4 \pm 0.2$ & $0.1 \pm 0.4$ & $0.0 \pm 0.8$ & $-0.1 \pm 0.9$ & $0.2 \pm 0.6$ & $0.1 \pm 0.9$ \\
\hline alr0965 & Unknown protein & $-0.1 \pm 0.1$ & $1.7 \pm 0.6$ & $1.0 \pm 0.3$ & $0.6 \pm 0.1$ & $0.8 \pm 0.2$ & $1.2 \pm 0.8$ & $0.9 \pm 0.3$ & $0.6 \pm 0.5$ \\
\hline all1163 & Hypothetical protein & $0.4 \pm 0.4$ & $2.3 \pm 0.4$ & $1.1 \pm 0.1$ & $0.4 \pm 0.2$ & $1.0 \pm 0.4$ & $1.2 \pm 0.3$ & $0.5 \pm 0.5$ & $0.1 \pm 0.2$ \\
\hline asl1274 & Unknown protein & $0.2 \pm 0.5$ & $2.5 \pm 0.8$ & $1.7 \pm 0.2$ & $0.3 \pm 0.5$ & $0.1 \pm 0.4$ & $0.6 \pm 0.4$ & $0.2 \pm 0.6$ & $-0.2 \pm 0.2$ \\
\hline alr1721 & Transcriptional regulator & $0.7 \pm 0.4$ & $3.3 \pm 0.9$ & $1.6 \pm 0.4$ & $1.1 \pm 0.3$ & $1.7 \pm 0.5$ & $1.2 \pm 0.6$ & $1.0 \pm 0.3$ & $0.6 \pm 0.1$ \\
\hline alr2310 & Similar to agmatinase & $-0.3 \pm 0.2$ & $1.7 \pm 0.4$ & $1.5 \pm 0.3$ & $0.7 \pm 0.2$ & $0.5 \pm 0.3$ & $0.7 \pm 0.2$ & $0.9 \pm 0.7$ & $-0.1 \pm 0.3$ \\
\hline all2371 & Unknown protein & $-0.7 \pm 0.6$ & $2.0 \pm 0.5$ & $1.3 \pm 0.2$ & $0.1 \pm 0.6$ & $0.6 \pm 0.2$ & $1.3 \pm 0.9$ & $0.6 \pm 0.7$ & \\
\hline alr2412 & Serine/threonine kinase & $-2.0 \pm 0.3$ & $2.0 \pm 0.2$ & $0.8 \pm 0.3$ & $0.5 \pm 0.1$ & $-0.5 \pm 1.0$ & $0.6 \pm 0.6$ & $0.3 \pm 0.9$ & $0.3 \pm 0.7$ \\
\hline $\operatorname{alr} 2478 \dagger$ & Hypothetical protein & $-0.7 \pm 0.1$ & $2.4 \pm 0.4$ & $1.7 \pm 0.3$ & $1.3 \pm 0.5$ & $-0.4 \pm 0.7$ & $0.5 \pm 0.7$ & $0.8 \pm 0.4$ & $1.0 \pm 0.8$ \\
\hline alr2483† & $\begin{array}{l}\text { Nicotinate-nucleotide } \\
\text { adenylyltransferase }\end{array}$ & $-0.3 \pm 0.7$ & $1.6 \pm 0.4$ & $0.4 \pm 0.1$ & $0.2 \pm 0.3$ & $0.1 \pm 0.1$ & $0.3 \pm 0.4$ & $0.0 \pm 0.3$ & $-0.2 \pm 0.3$ \\
\hline alr2488 & Hypothetical protein & $0.1 \pm 0.3$ & $2.3 \pm 0.5$ & $1.4 \pm 0.1$ & $1.3 \pm 0.4$ & $-0.2 \pm 0.6$ & $0.6 \pm 0.3$ & $0.5 \pm 0.6$ & $0.4 \pm 0.3$ \\
\hline asr3796 & Stress-induced hydrophobic peptide & $-0.9 \pm 0.4$ & $2.3 \pm 0.3$ & $1.5 \pm 0.2$ & $0.0 \pm 0.2$ & $-0.2 \pm 0.4$ & $0.7 \pm 0.5$ & $0.4 \pm 0.7$ & $-0.6 \pm 0.3$ \\
\hline alr3900 & Hypothetical protein & $0.0 \pm 0.2$ & $1.7 \pm 0.3$ & $1.2 \pm 0.2$ & $0.9 \pm 0.2$ & $0.9 \pm 0.1$ & $0.9 \pm 0.2$ & $0.5 \pm 0.4$ & $0.9 \pm 0.4$ \\
\hline all4040 & Unknown protein & $-0.7 \pm 0.1$ & $2.2 \pm 0.6$ & $1.3 \pm 0.2$ & $0.9 \pm 0.3$ & $-0.3 \pm 0.3$ & $0.4 \pm 0.7$ & $-0.5 \pm 1.0$ & $0.1 \pm 0.9$ \\
\hline all4333 & Hypothetical protein & $-1.1 \pm 0.3$ & $2.3 \pm 0.3$ & $1.8 \pm 0.2$ & $1.0 \pm 0.2$ & $-1.2 \pm 0.3$ & $0.0 \pm 0.4$ & $0.7 \pm 0.5$ & $0.2 \pm 0.5$ \\
\hline asr4352 & Unknown protein & $-1.3 \pm 0.4$ & $1.7 \pm 0.4$ & $1.3 \pm 0.2$ & $0.3 \pm 0.4$ & $-0.8 \pm 0.6$ & $0.3 \pm 0.5$ & $0.0 \pm 0.8$ & $-0.5 \pm 0.8$ \\
\hline all4590 & Protease IV & $-0.7 \pm 0.4$ & $1.9 \pm 0.3$ & $1.5 \pm 0.4$ & $1.2 \pm 0.2$ & $0.2 \pm 0.4$ & $1.2 \pm 0.1$ & $0.4 \pm 0.5$ & $0.3 \pm 0.3$ \\
\hline all 4759 & WD-repeat protein & $-0.5 \pm 0.1$ & $2.7 \pm 1.0$ & $1.1 \pm 0.2$ & $0.6 \pm 0.4$ & $0.2 \pm 0.3$ & $0.9 \pm 0.7$ & $-0.1 \pm 1.0$ & $0.3 \pm 0.3$ \\
\hline all5173† & $\begin{array}{l}\text { Two-component hybrid sensor and } \\
\text { regulator }\end{array}$ & $1.1 \pm 0.4$ & $3.3 \pm 0.1$ & $1.6 \pm 0.3$ & $0.7 \pm 1.0$ & $0.7 \pm 0.8$ & $0.3 \pm 0.5$ & & \\
\hline all5174 & Two-component response regulator & $-0.1 \pm 1.0$ & $3.7 \pm 0.6$ & $2.0 \pm 0.2$ & $0.5 \pm 0.2$ & $-0.4 \pm 0.6$ & $1.0 \pm 0.3$ & $0.4 \pm 0.7$ & \\
\hline alr0540 & $\begin{array}{l}\text { 1-Pyrroline-5-carboxylate } \\
\text { dehydrogenase }\end{array}$ & $-0.5 \pm 1.0$ & $1.2 \pm 0.8$ & $1.9 \pm 0.3$ & $0.9 \pm 0.3$ & $1.1 \pm 0.7$ & $1.2 \pm 0.3$ & $1.4 \pm 0.5$ & $0.5 \pm 0.5$ \\
\hline all1411 & Unknown protein & $1.0 \pm 0.6$ & $0.3 \pm 0.5$ & $2.6 \pm 0.4$ & $2.6 \pm 0.8$ & $0.2 \pm 0.7$ & $0.7 \pm 0.4$ & $0.2 \pm 0.9$ & $0.3 \pm 0.5$ \\
\hline alr1594 & RNA polymerase $\beta$ subunit & $-1.2 \pm 0.1$ & $1.1 \pm 0.4$ & $1.6 \pm 0.2$ & $0.9 \pm 0.3$ & $-0.2 \pm 0.1$ & $-0.4 \pm 0.1$ & $0.3 \pm 0.4$ & $0.1 \pm 0.1$ \\
\hline alr3815 & Unknown protein & $-0.3 \pm 0.4$ & $1.9 \pm 0.3$ & $1.9 \pm 0.3$ & $0.3 \pm 0.2$ & $-0.5 \pm 0.5$ & $0.6 \pm 0.8$ & $0.1 \pm 0.7$ & $-0.3 \pm 0.8$ \\
\hline alr4281 & DevC homologue & $-0.8 \pm 0.5$ & $1.5 \pm 1.6$ & $3.1 \pm 0.3$ & $-0.7 \pm 0.4$ & $-0.5 \pm 0.9$ & $0.2 \pm 0.5$ & $-0.5 \pm 1.2$ & $-1.3 \pm 0.9$ \\
\hline alr4974 & DevC homologue & $0.9 \pm 0.3$ & $1.6 \pm 1.8$ & $3.9 \pm 0.4$ & $0.4 \pm 0.7$ & $0.3 \pm 1.5$ & $0.5 \pm 0.2$ & $0.5 \pm 1.0$ & $-0.2 \pm 0.8$ \\
\hline all5265 & DNA gyrase B subunit & $-1.4 \pm 0.3$ & $1.4 \pm 0.4$ & $2.0 \pm 0.5$ & $0.7 \pm 0.2$ & $0.2 \pm 0.9$ & $1.0 \pm 0.3$ & $0.7 \pm 0.7$ & $-0.5 \pm 0.2$ \\
\hline all $4422 \dagger$ & $\begin{array}{l}\text { UDP- } N \text {-acetyl-D-mannosamine } \\
\text { transferase }\end{array}$ & $-0.5 \pm 0.6$ & $0.6 \pm 0.9$ & $2.4 \pm 0.2$ & $2.6 \pm 0.6$ & $0.3 \pm 1.0$ & $0.9 \pm 0.0$ & $0.8 \pm 0.5$ & $0.8 \pm 0.2$ \\
\hline alr4057† & Similar to peptide synthetase & $-0.5 \pm 0.4$ & $0.1 \pm 0.3$ & $0.6 \pm 0.6$ & $1.7 \pm 0.4$ & $-0.2 \pm 0.7$ & $0.6 \pm 0.4$ & $0.7 \pm 0.3$ & $0.1 \pm 0.5$ \\
\hline alr4576 & Hypothetical protein & $-0.2 \pm 0.4$ & $0.6 \pm 0.7-$ & $-0.1 \pm 0.6$ & $1.6 \pm 0.6$ & $-0.2 \pm 0.5$ & $-0.4 \pm 0.3$ & $-0.1 \pm 1.0$ & $0.1 \pm 0.6$ \\
\hline alr5223 & Glycosyltransferase & $0.5 \pm 0.2$ & $-0.8 \pm 0.7$ & $0.4 \pm 0.3$ & $2.2 \pm 0.5$ & $0.6 \pm 1.0$ & $-0.2 \pm 0.8$ & $0.9 \pm 0.2$ & $0.8 \pm 0.6$ \\
\hline
\end{tabular}

${ }^{\star}$ Means \pm SD of ratio in $\log _{2}$.

$\dagger$ Genes induced by nitrogen depletion (Ehira \& Ohmori, 2006).

weight of the cells was constant after $9 \mathrm{~h}$ of dehydration (Katoh et al., 2004) and the viability of the wild-type cells was $64 \%$ at $24 \mathrm{~h}$ (Higo et al., 2006). In the wild-type strain, approximately $30 \%$ of the oxygen-evolving activity recovered within $30 \mathrm{~min}$ of rehydration, then there was further gradual recovery during rehydration. The activity returned to the level before rehydration within $24 \mathrm{~h}$ (data not shown). Tamaru et al. (2005) reported that while $N$. commune colonies with EPS recovered $100 \%$ of oxygenevolving activity rapidly after rehydration following overnight air-drying, EPS-depleted cells recovered only $30 \%$ of the activity, a level similar to that in Anabaena PCC 7120, which contains little EPS. These results suggest that desiccation tolerance attributed to intracellular mechanisms is similar between Anabaena PCC 7120 and N. commune. 
Table 3. Effects of the disruption of alr0618 on the upregulation of gene expression during rehydration

Results in bold represent significant upregulation of genes at the time points compared to dehydration phase in the wild-type strain, but not in the gene disruptant strains.

\begin{tabular}{|c|c|c|c|c|c|c|c|c|c|}
\hline \multirow[t]{2}{*}{ Gene } & \multirow[t]{2}{*}{ Description } & \multicolumn{4}{|c|}{ Wild-type strain ${ }^{\star}$} & \multicolumn{4}{|c|}{ alr0618 disruptant* } \\
\hline & & $\begin{array}{c}\text { Dehydration } \\
\qquad 24 \mathrm{~h}\end{array}$ & \multicolumn{3}{|c|}{ Rehydration } & $\begin{array}{c}\text { Dehydration } \\
24 \mathrm{~h}\end{array}$ & \multicolumn{3}{|c|}{ Rehydration } \\
\hline alr0965 & Unknown protein & $-0.1 \pm 0.1$ & $1.7 \pm 0.6$ & $1.0 \pm 0.3$ & $0.6 \pm 0.1$ & $0.4 \pm 1.7$ & $0.6 \pm 0.8$ & $0.0 \pm 0.7$ & $-0.4 \pm 1.3$ \\
\hline alr1054 & DNA polymerase III $\alpha$ subunit & $-0.1 \pm 0.4$ & $1.6 \pm 0.2$ & $1.0 \pm 0.3$ & $0.2 \pm 0.2$ & $0.2 \pm 0.7$ & $0.7 \pm 0.5$ & $0.2 \pm 0.5$ & $-0.2 \pm 1.0$ \\
\hline all4590 & Protease IV & $-0.7 \pm 0.4$ & $1.9 \pm 0.3$ & $1.5 \pm 0.4$ & $1.2 \pm 0.2$ & $-0.2 \pm 1.0$ & $0.5 \pm 0.5$ & $0.6 \pm 0.9$ & $0.5 \pm 0.2$ \\
\hline all4983 & Unknown protein & $-0.9 \pm 0.9$ & $2.0 \pm 0.6$ & $0.5 \pm 0.1-$ & $-0.4 \pm 0.3$ & $-0.5 \pm 0.9$ & $-0.3 \pm 0.4$ & $-0.5 \pm 1.1$ & $-0.8 \pm 0.4$ \\
\hline alr2554 & Unknown protein & $-0.4 \pm 0.5$ & $1.8 \pm 0.6$ & $1.0 \pm 0.2$ & $2.3 \pm 0.8$ & $0.8 \pm 0.4$ & $1.2 \pm 0.6$ & $0.0 \pm 0.8$ & $0.4 \pm 0.8$ \\
\hline alr0030 & $\begin{array}{l}\text { Similar to Mg-protoporphyrin IX } \\
\text { monomethyl ester oxidative cyclase }\end{array}$ & $-0.1 \pm 0.3$ & $0.1 \pm 1.1$ & $1.7 \pm 0.2$ & $1.3 \pm 0.6$ & $0.0 \pm 0.4$ & $0.4 \pm 0.3$ & $0.1 \pm 0.0$ & $0.6 \pm 0.6$ \\
\hline alr0607 & Nitrite reductase NirA & $-0.1 \pm 0.2$ & $0.4 \pm 0.3-$ & $-0.4 \pm 1.1$ & $1.6 \pm 0.5$ & $-1.2 \pm 0.4$ & $-0.9 \pm 0.4$ & $-1.0 \pm 0.4$ & $-0.7 \pm 0.6$ \\
\hline alr0608 & $\begin{array}{l}\text { Nitrate transport nitrate-binding } \\
\text { protein NrtA }\end{array}$ & $-0.4 \pm 0.5$ & $-0.2 \pm 0.2$ & $0.3 \pm 0.9$ & $1.6 \pm 0.3$ & $-1.3 \pm 0.7$ & $-1.3 \pm 1.0$ & $-1.0 \pm 1.2$ & $-1.2 \pm 1.4$ \\
\hline alr0611 & $\begin{array}{l}\text { Nitrate transport ATP-binding } \\
\text { protein NrtD }\end{array}$ & $-0.3 \pm 0.4$ & $0.6 \pm 0.6$ & $1.4 \pm 1.8$ & $2.0 \pm 0.3$ & $0.4 \pm 0.9$ & $-1.2 \pm 1.2$ & $-0.5 \pm 1.6$ & $-1.3 \pm 1.1$ \\
\hline all1848 & Similar to methyltransferase & $0.9 \pm 0.4$ & $0.3 \pm 0.4$ & $1.0 \pm 0.2$ & $2.5 \pm 0.5$ & $0.7 \pm 0.3$ & $0.2 \pm 0.2$ & $0.6 \pm 0.6$ & $1.3 \pm 0.6$ \\
\hline alr3720 & Unknown protein & $0.3 \pm 0.3$ & $0.0 \pm 0.4$ & $0.8 \pm 0.5$ & $2.4 \pm 0.5$ & $0.5 \pm 1.5$ & $0.7 \pm 1.6$ & $0.7 \pm 1.1$ & $1.0 \pm 1.0$ \\
\hline all3797 & Hypothetical protein & $-0.8 \pm 0.2$ & $0.4 \pm 0.3$ & $1.2 \pm 0.7$ & $1.8 \pm 0.4$ & $-0.1 \pm 0.8$ & $0.6 \pm 0.4$ & $0.4 \pm 0.1$ & $0.6 \pm 0.5$ \\
\hline alr4057 & Similar to peptide synthetase & $-0.5 \pm 0.4$ & $0.1 \pm 0.3$ & $0.6 \pm 0.6$ & $1.7 \pm 0.4$ & $-0.4 \pm 0.4$ & $-0.9 \pm 0.4$ & $-0.3 \pm 0.5$ & $0.0 \pm 0.5$ \\
\hline all4989 & Hypothetical protein & $-0.9 \pm 0.9$ & & $1.1 \pm 0.8$ & $2.1 \pm 0.6$ & $0.2 \pm 1.3$ & $-0.3 \pm 0.6$ & $0.1 \pm 0.3$ & $0.7 \pm 0.6$ \\
\hline alr5223 & Glycosyltransferase & $0.5 \pm 0.2$ & $-0.8 \pm 0.7$ & $0.4 \pm 0.3$ & $2.2 \pm 0.5$ & $0.2 \pm 0.6$ & $-0.8 \pm 0.7$ & $0.6 \pm 0.9$ & $0.3 \pm 0.8$ \\
\hline
\end{tabular}

${ }^{\star}$ Means \pm SD of ratio in $\log _{2}$.

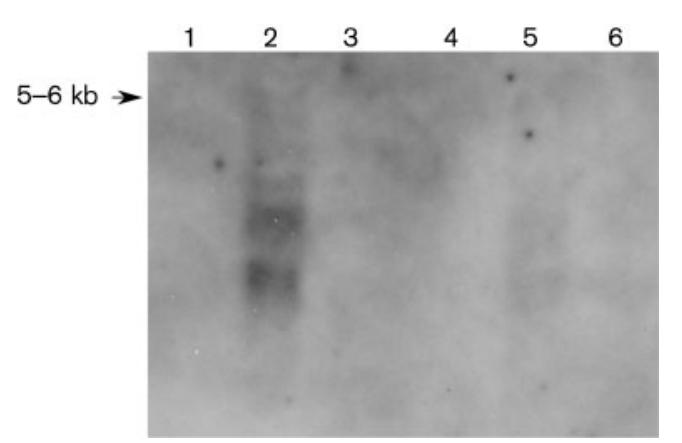

Fig. 3. Northern blotting analysis of $c m p A$. RNA was extracted from cells dehydrated for $24 \mathrm{~h}$ (lanes 1 and 4 ), and from cells rehydrated for $20 \mathrm{~min}$ (lanes 2 and 5) and $1 \mathrm{~h}$ (lane 3 and 6) following dehydration for $24 \mathrm{~h}$. Lanes $1-3$, wild-type strain; lanes 4-6, alr0618 disruptant.

\section{Repression of cellular metabolism during dehydration and resumption of it following rehydration}

The repression of cellular metabolism during desiccation is an essential mechanism for desiccation tolerance based on the avoidance of reactive oxygen species (ROS) formation, and is not just an effect of water removal (Oliver et al., 2001). Indeed, expression of genes involved in central cellular energy metabolism was downregulated during dehydration in Anabaena PCC 7120. First, genes encoding components of photosystem II, ATP synthesis and RuBisCo were downregulated. Then, expression of genes encoding components of photosystem I and nitrogen fixation were downregulated before drying of cells was complete (Fig. 5). It would thus be reasonable to suggest that transcription of genes involved in electron-transfer processes such as photosystem II, which is a main source of ROS, were downregulated first. Downregulation of genes 


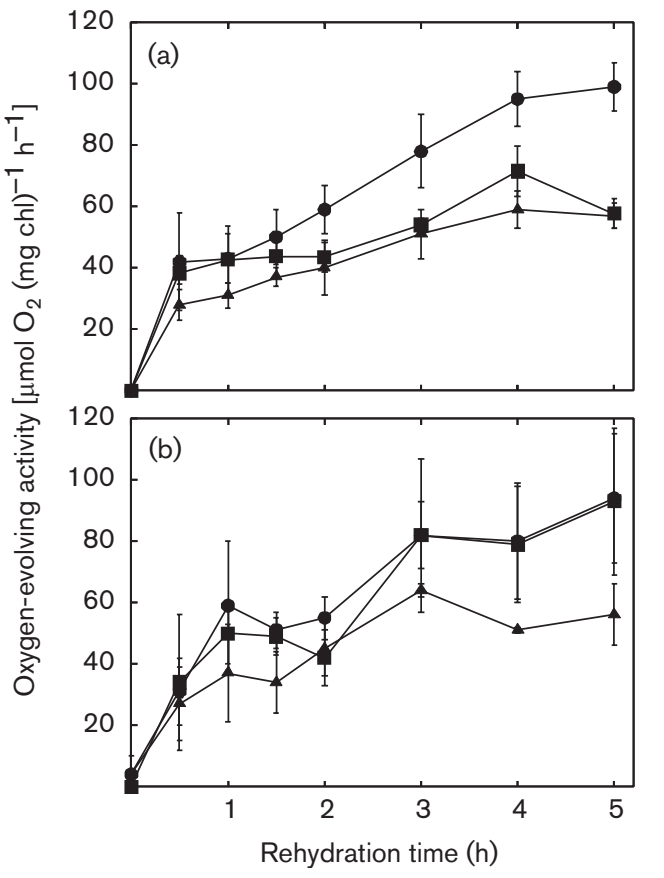

Fig. 4. Recovery of oxygen-evolving activity during rehydration. After $24 \mathrm{~h}$ of dehydration, cells were rehydrated in $\mathrm{MDM}_{0}$ medium and grown as before dehydration. The oxygen-evolving activity before dehydration was at the same level amongst the three strains. The oxygen-evolving activity was mesured (a) without or (b) with $5 \mathrm{mM} \mathrm{NaHCO}, 10 \mathrm{mM}$ HEPES (pH 7.5). @, Anabaena PCC 7120; $\boldsymbol{\Delta}$, ancrpB disruptant; $\mathbf{\square}$, alr0618 disruptant. The results are means $\pm \mathrm{SD}(n=3)$.

involved in nitrogen fixation would follow after a decrease in ATP and reducing power.

On the other hand, the stepwise and coordinated resumption of cellular metabolism during rehydration is also considered to be necessary to reduce ROS formation. In fact, the upregulation of the suf cluster during rehydration (Supplementary Table S5) indicates that oxidative stress occurs within cells during rehydration. In Anabaena PCC 7120, the transcriptional levels of genes involved in ATP synthesis, photosynthesis and nitrogen fixation, which were downregulated during dehydration, recovered after rehydration. The expression of genes for the components of RuBisCO recovered first $(20 \mathrm{~min})$; then the expression of genes for ATP synthesis and photosystem II recovered $(1 \mathrm{~h})$; and finally, the expression of the genes for photosystem I and nitrogen fixation (3 h). Expression of the genes for cytochrome $c$ oxidase was upregulated at $20 \mathrm{~min}$ and $1 \mathrm{~h}$ of rehydration (Supplementary Table S5, Fig. 5). Respiratory activity recovered consistently within $1 \mathrm{~h}$ of rehydration (data not shown), whereas the recovery of net photosynthetic activity required more than $5 \mathrm{~h}$ of rehydration (Fig. 4). It has been reported that after rehydration, cells of $N$. commune resume respiration, photosynthesis and nitrogen fixation in a stepwise,

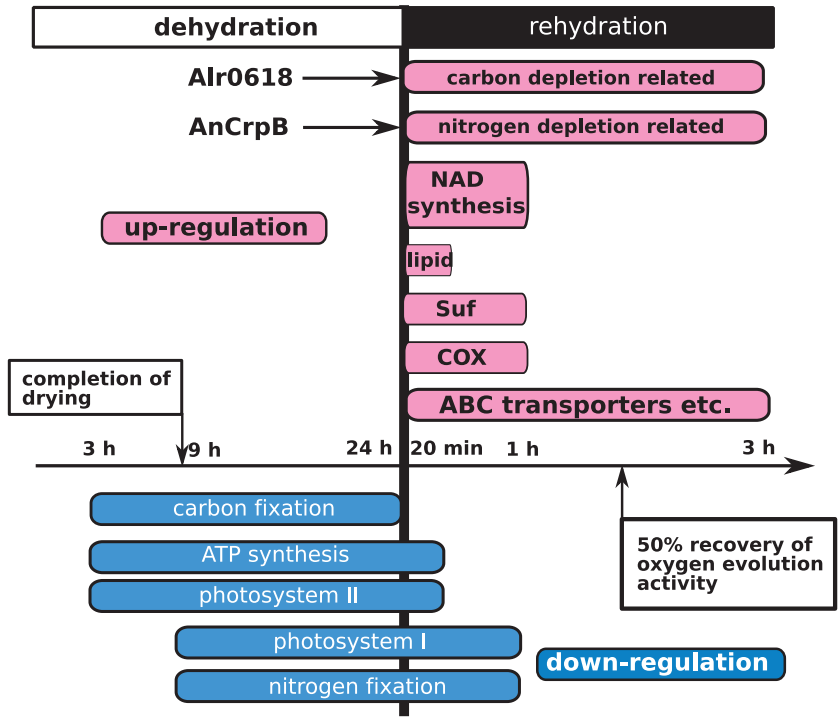

Fig. 5. Schematic model of the transcriptional changes in metabolic gene expression during dehydration and rehydration.

coordinated manner (Scherer et al., 1984), as well as ATP synthesis (Scherer et al., 1986) and lipid biosynthesis (Taranto et al., 1993). Anabaena PCC 7120 cells should also recover their cellular activities in a stepwise, coordinated manner after rehydration, like $N$. commune. ATP supplied by the respiratory chain would be necessary for the recovery of fundamental cellular mechanisms including photosynthesis immediately after rehydration. Then photosystem I would supply ATP and reducing power for the resumption of nitrogen fixation. With regard to lipid biosynthesis, the expression of allo270, encoding diacylglycerol kinase (DAGK) is upregulated upon rehydration (Supplementary Table S5). DAGK catalyses the formation of phosphatidic acid from diacylglycerol and ATP, an important step in phospholipid biosynthesis. DAGK would be involved in the rapid biosynthesis of lipids induced upon rehydration, as in N. commune (Taranto et al., 1993).

The expression of many genes involved in cellular metabolism is also upregulated in response to rehydration (Supplementary Table S5). Among these, the expression of the genes of the NAD biosynthetic pathway, alr2482, alr2483 and all4673, was markedly upregulated upon rehydration (Fig. 2). NAD is used by DNA ligase, which is required for DNA repair (Eisen \& Hanawalt, 1999). The expression of genes for DNA repair was upregulated after rehydration (Supplementary Table S5), suggesting that NAD is consumed to repair damaged DNA, and must be supplied via the NAD biosynthetic pathway.

\section{Role of the two CRP family transcriptional regulators during rehydration}

It has been suggested that $\mathrm{AnCrpB}$ regulates the expression of some genes induced by nitrogen depletion (Table 2). 
Heterocysts are more sensitive to desiccation than are vegetative cells (Potts \& Bowman, 1985) and the recovery of nitrogenase activity during rehydration is slow in $N$. commune (Scherer et al., 1984). Accordingly, a shortage of nitrogen supply should result in nitrogen depletion in Anabaena cells at early rehydration. Considering that the expression of $n t c A$, a global nitrogen-responsive transcriptional regulator gene, is downregulated during rehydration and that there was no NtcA consensus sequence (Herrero et al., 2001) upstream of the genes listed in Table 2, AnCrpB may perform a regulatory role under nitrogen depletion, independent of NtcA. Otherwise, AnCrpB may be involved in a stress response common to both nitrogen depletion and rehydration.

The expression of alr4156, a gene induced by $\mathrm{CO}_{2}$ limitation (Wang et al., 2004), is upregulated after rehydration in the wild-type strain, while it is not upregulated in the alr0618 disruptant. The expression patterns of alr4157 and alr4158, which are also induced by $\mathrm{CO}_{2}$ limitation, were similar to that of alr4156 (Supplementary Table S7). Northern blotting clarified that expression of the cmp operon is upregulated after rehydration in the wild-type strain while it is not upregulated in the alr0618 disruptant (Fig. 3). These genes in two gene clusters encode a component of $\mathrm{NAD}(\mathrm{P}) \mathrm{H}$ dehydrogenase essential for low- $\mathrm{CO}_{2}$ growth and high-affinity bicarbonate uptake, respectively (Shibata et al., 2001). In addition, oxygen-evolving activity during rehydration in the alr0618 disruptant was lower than that in the wild-type strain only when bicarbonate was not added (Fig. 4). These results suggest that alr0618 is involved in inorganic carbon uptake.

The upregulation of alr0965, all4590, alr4057 and alr5223 expression during rehydration was abolished in the alr0618 disruptant, as well as in the $\operatorname{ancrpB}$ disruptant. Upregulation of nirA, encoding nitrate reductase, and nrtA and $n r t D$, encoding components of the nitrate transporter, was also abolished in the alr0618 disruptant. These results suggest the co-regulation of genes involved in nitrogen and carbon metabolism.

In conclusion, the gene expression response during rehydration is dynamic, whereas that during dehydration is not. Fig. 5 shows a schematic model of the transcriptional changes in the expression of metabolic genes during dehydration and rehydration. During rehydration, the expression of genes downregulated during dehydration is restored in Anabaena PCC 7120 cells. At the same time, the expression of various metabolic genes involved in NAD depletion, nitrogen depletion and $\mathrm{CO}_{2}$ limitation, as well as genes for the repair of DNA and proteins, is upregulated. It is suggested that two CRP family transcriptional regulators, AnCrpB and Alr0618, are required for the coordinated resumption of nitrogen and inorganic carbon metabolism during rehydration.

\section{ACKNOWLEDGEMENTS}

We thank Dr Shimshon Belkin (The Hebrew University of Jerusalem) for critical reading of the manuscript. This work was supported by a grant to M. O. from the Research Institute of Innovative Technology for the Earth.

\section{REFERENCES}

Cai, Y. P. \& Wolk, C. P. (1990). Use of a conditionally lethal gene in Anabaena sp. strain PCC 7120 to select for double recombinants and to entrap insertion sequences. J Bacteriol 172, 3138-3145.

Eddy, S. R. (1998). Profile hidden Markov models. Bioinformatics 14, 755-763.

Ehira, S. \& Ohmori, M. (2006). NrrA, a nitrogen-responsive response regulator facilitates heterocyst development in the cyanobacterium Anabaena sp. strain PCC 7120. Mol Microbiol 59, 1692-1703.

Ehira, S., Ohmori, M. \& Sato, N. (2003). Genome-wide expression analysis of the responses to nitrogen deprivation in the heterocystforming cyanobacterium Anabaena sp. strain PCC 7120. DNA Res 10, 97-113.

Eisen, J. A. \& Hanawalt, P. C. (1999). A phylogenomic study of DNA repair genes, proteins, and processes. Mutat Res 435, 171-213.

Elhai, J. \& Wolk, C. P. (1988). Conjugal transfer of DNA to cyanobacteria. Methods Enzymol 167, 747-754.

Elhai, J., Vepritskiy, A., Muro-Pastor, A. M., Flores, E. \& Wolk, C. P. (1997). Reduction of conjugal transfer efficiency by three restriction activities of Anabaena sp. strain PCC 7120. J Bacteriol 179, 1998-2005.

Gerdes, S. Y., Kurnasov, O. V., Shatalin, K., Polanuyer, B., Sloutsky, R., Vonstein, V., Overbeek, R. \& Osterman, A. L. (2006). Comparative genomics of NAD biosynthesis in cyanobacteria. J Bacteriol 188, 3012-3023.

Helm, R. F., Huang, Z., Edwards, D., Lesson, H., Peery, W. \& Potts, M. (2000). Structural characterization of the released polysaccharide of desiccation-tolerant Nostoc commune DRH-1. J Bacteriol 182, 974-982.

Hengge-Aronis, R. (2002). Signal transduction and regulatory mechanisms involved in control of the $\sigma^{\mathrm{S}}$ (RpoS) subunit of RNA polymerase. Microbiol Mol Biol Rev 66, 373-395.

Herrero, A., Muro-Pastor, A. M. \& Flores, E. (2001). Nitrogen control in cyanobacteria. J Bacteriol 183, 411-425.

Higo, A., Katoh, H., Ohmori, K., Ikeuchi, M. \& Ohmori, M. (2006). The role of a gene cluster for trehalose metabolism in dehydration tolerance of the filamentous cyanobacterium Anabaena sp. PCC 7120. Microbiology 152, 979-987.

Hill, D. R., Hladun, S. L., Scherer, S. \& Potts, M. (1994a). Water stress proteins of Nostoc commune (Cyanobacteria) are secreted with UV-A/ B-absorbing pigments and associate with 1,4- $\beta$-D-xylanxylanohydrolase activity. J Biol Chem 269, 7726-7734.

Hill, D. R., Peat, A. \& Potts, M. (1994b). Biochemistry and structure of the glycan secreted by desiccation-tolerant Nostoc commune (cyanobacteria). Protoplasma 182, 126-148.

Hill, D. R., Keenan, T. W., Helm, R. F., Potts, M., Crowe, L. M. \& Crowe, J. H. (1997). Extracellular polysaccharide of Nostoc commune (Cyanobacteria) inhibits fusion of membrane vesicles during desiccation. J Appl Phycol 9, 237-248.

Kaneko, T., Nakamura, Y., Wolk, C. P., Kuritz, T., Sasamoto, S., Watanabe, A., Iriguchi, M., Ishikawa, A., Kawashima, K. \& other authors (2001). Complete genomic sequence of the filamentous nitrogen-fixing cyanobacterium Anabaena sp. strain PCC 7120. DNA Res 8, 227-253.

Katoh, H., Shiga, Y., Nakahira, Y. \& Ohmori, M. (2003). Isolation and characterization of a drought-tolerant cyanobacterium, Nostoc sp. HK-01. Microbes Environ 18, 82-88. 
Katoh, H., Asthana, R. K. \& Ohmori, M. (2004). Gene expression in the cyanobacterium Anabaena sp. PCC 7120 under desiccation. Microb Ecol 47, 164-174.

Kratz, W. A. \& Myers, J. (1955). Nutrition and growth of several bluegreen algae. Am J Bot 42, 282-287.

Mackinney, G. (1941). Absorption of light by chlorophyll solution. J Biol Chem 140, 315-322.

Nachin, L., El Hassouni, M., Loiseau, L., Expert, D. \& Barras, F. (2001). SoxR-dependent response to oxidative stress and virulence of Erwinia chrysanthemi: the key role of SufC, an orphan ABC ATPase. Mol Microbiol 39, 960-972.

Oliver, A. E., Leprince, O., Wolkers, W. F., Hincha, D. K., Heyer, A. G. \& Crowe, J. H. (2001). Non-disaccharide-based mechanisms of protection during drying. Cryobiology 43, 151-167.

Paithoonrangsarid, K., Shoumskaya, M. A., Kanesaki, Y., Satoh, S., Tabata, S., Los, D. A., Zinchenko, V. V., Hayashi, H., Tanticharoen, M. $\&$ other authors (2004). Five histidine kinases perceive osmotic stress and regulate distinct sets of genes in Synechocystis. J Biol Chem 279, 53078-53086.

Potts, M. (1994). Desiccation tolerance of prokaryotes. Microbiol Rev 58, 755-805.

Potts, M. (1999). Mechanisms of desiccation tolerance in cyanobacteria. Eur J Phycol 34, 319-328.

Potts, M. (2001). Desiccation tolerance: a simple process? Trends Microbiol 9, 553-559.

Potts, M. \& Bowman, M. A. (1985). Sensitivity of Nostoc commune UTEX 584 (cyanobacteria) to water stress. Arch Microbiol 141, 51-56.

Satoh, K., Hirai, M., Nishio, J., Yamaji, T., Kashino, Y. \& Koike, H. (2002). Recovery of photosynthetic systems during rewetting is quite rapid in a terrestrial cyanobacterium, Nostoc commune. Plant Cell Physiol 43, 170-176.

Scherer, S. \& Potts, M. (1989). Novel water stress protein from a desiccation-tolerant cyanobacterium. J Biol Chem 264, 12546-12553.

Scherer, S., Ernst, A., Chen, T. W. \& Böger, P. (1984). Rewetting of drought resistant blue-green algae: time course of water uptake and reappearance of respiration, photosynthesis, and nitrogen fixation. Oecologia 62, 418-423.

Scherer, S., Chen, T. W. \& Böger, P. (1986). Recovery of adeninenucleotide pools in terrestrial blue-green algae after prolonged drought periods. Oecologia 68, 585-588.

Shaw, E., Hill, D. R., Brittain, N., Wright, D. J., Tauber, U., Marand, H., Helm, R. F. \& Potts, M. (2003). Unusual water flux in the extracellular polysaccharide of the cyanobacterium Nostoc commune. Appl Environ Microbiol 69, 5679-5684.
Shibata, M., Ohkawa, H., Kaneko, T., Fukuzawa, H., Tabata, S., Kaplan, A. \& Ogawa, T. (2001). Distinct constitutive and low- $\mathrm{CO}_{2^{-}}$ induced $\mathrm{CO}_{2}$ uptake systems in cyanobacteria: genes involved and their phylogenetic relationship with homologous genes in other organisms. Proc Natl Acad Sci U S A 98, 11789-11794.

Shirkey, B., Kovarcik, D. P., Wright, D. J., Wilmoth, G., Prickett, T. F., Helm, R. F., Gregory, E. M. \& Potts, M. (2000). Active Fe-containing superoxide dismutase and abundant sodF mRNA in Nostoc commune (Cyanobacteria) after years of desiccation. J Bacteriol 182, 189-197.

Singh, J., Kumar, D., Ramakrishnan, N., Singhal, V., Jervis, J., Garst, J. F., Slaughter, S. M., DeSantis, A. M., Potts, M. \& Helm, R. F. (2005). Transcriptional response of Saccharomyces cerevisiae to desiccation and rehydration. Appl Environ Microbiol 71, 8752-8763.

Suzuki, T., Yoshimura, H., Hisabori, T. \& Ohmori, M. (2004). Two cAMP receptor proteins with different biochemical properties in the filamentous cyanobacterium Anabaena sp. PCC 7120. FEBS Lett 571, 154-160.

Suzuki, I., Kanesaki, Y., Hayashi, H., Hall, J. J., Simon, W. J., Slabas, A. R. \& Murata, N. (2005). The histidine kinase Hik34 is involved in thermotolerance by regulating the expression of heat shock genes in Synechocystis. Plant Physiol 138, 1409-1421.

Tamaru, Y., Takani, Y., Yoshida, T. \& Sakamoto, T. (2005). Crucial role of extracellular polysaccharides in desiccation and freezing tolerance in the terrestrial cyanobacterium Nostoc commune. Appl Environ Microbiol 71, 7327-7333.

Taranto, P. A., Keenan, T. W. \& Potts, M. (1993). Rehydration induces rapid onset of lipid biosynthesis in desiccated Nostoc commune (cyanobacteria). Biochim Biophys Acta 1168, 228-237.

Wang, H. L., Postier, B. L. \& Burnap, R. L. (2004). Alterations in global patterns of gene expression in Synechocystis sp. PCC 6803 in response to inorganic carbon limitation and the inactivation of $n d h R$, a LysR family regulator. J Biol Chem 279, 5739-5751.

Watanabe, A. (1960). List of algal strains in collection at the Institute of Applied Microbiology, University of Tokyo. J Gen Appl Microbiol 6, 283-292.

Wright, D. J., Smith, S. C., Joardar, V., Scherer, S., Jervis, J., Warren, A., Helm, R. F. \& Potts, M. (2005). UV irradiation and desiccation modulate the three-dimensional extracellular matrix of Nostoc commune (Cyanobacteria). J Biol Chem 280, 40271-40281.

Xie, W. Q., Tice, D. \& Potts, M. (1995). Cell-water deficit regulates expression of rpoC1C2 (RNA polymerase) at the level of mRNA in desiccation-tolerant Nostoc commune UTEX 584 (Cyanobacteria). FEMS Microbiol Lett 126, 159-164.

Edited by: D. J. Scanlan 